\title{
Some key technology trends in tourism industry
}

\author{
Brankica Pažun ${ }^{1}$, Zlatko Langović ${ }^{2}$ (i) \\ ${ }^{1}$ Faculty of Engineering Management, Bul. Vojvode Mišića 43, Belgrade, Serbia \\ ${ }^{2}$ Faculty of Hotel Management and Tourism, Vojvodjanska bb, Vrnjačka Banja, Serbia
}

\author{
Keywords: \\ Artificial intelligence, \\ Big data, \\ Cloud system, \\ Information technology, \\ Internet of things.
}

\begin{abstract}
The application of contemporary information technologies in the tourism industry enables the management of the tourism sector in a dynamic business environment. The observed tourism systems generate large amounts of data, which are managed using a set of synchronized concepts such are artificial intelligence systems, big data systems, internet of things and cloud platforms, big data concept. Mentioned systems are becoming an integral part of the business, i.e., they offer new opportunities that become an integral part of the service. By applying the given technologies, both companies and users of tourist services benefit, and productivity and business efficiency of tourist systems increase. The aim of the paper is to identify the current and future changes in the tourism industry by information technology concepts implementation.
\end{abstract}

\section{Introduction}

Tourism has been considered the largest and fastest growing branch in the world, as well as one of the largest employers in the world. Income from tourism has had a significant share in the total income of many countries, and in this branch, both domestically and globally, it has had approximately the largest number of employees, by 2020. For example, according to Statista (2021) total contribution of travel and tourism to GDP in Europe from 2012 to 2020 (in billion U.S. dollars) has been constantly increasing at high level, from 1.843.1 to 2.192.1, except of decline in 2020, that is 1064.7. Total contribution of travel and tourism to employment in Europe from 2012 to 2020 (in million jobs), as well, has had growth, from 33.8 to 38.47 (34.7 in 2020, that is $9.3 \%$ less comparing to previous year).

COVID19 pandemic has had and will have serious impact on travel, tourism, and hospitality worldwide. According to the World Tourism Organization - UNWTO (2021) international tourism has been very vulnerable, and still weakens in 2021 (in 2020 by $73 \%$ decreasing arrivals to $87 \%$ at the start of 2021). Some predictions in brighter shift in the second half of 2021 are presented by two scenarios (UNWTO, 2021). They consider a possible and relative recovery in international travel, the first by July, and second scenario by September. They are based on factors, such are lifting of travel restrictions, the success of vaccination programs, as well as the introduction of harmonized protocols such as the Digital Green Certificate planned by the European Commission.

Therefore, there is a challenge how to solve nowadays problem caused by pandemic. Information technology has been key driver in any world process, such are in education, economy, production, environmental field, etc. As efficient, sometimes necessary tool, especially in the crisis period, information technologies help in everyday life, in online teaching, working, shopping, passenger screening, etc. (Pažun, Langović, 2020)

\section{Contemporary IT concepts}

The importance of computerization of the tourism sector, as well as monitoring the latest achievements in the field of information technology, can be seen in the fact of increasing the share of given industry in global GDP (Pažun, Langović, 2019). As it has been growing intensively in recent decades, 
it is important to observe the ways to improve business through the application of new IT technologies. Some of IT concepts are presented further.

Big Data. Nowadays large amounts of data are generated. Given complex datasets, looking through the aspect of Big Data paradigm, can be defined through scope, diversity and speed. Organizations that use these complex data structures define business value through predictive analytics, i.e., through strategy defining. The systems presented in the Big Data architecture are mainly: traditional relational database management systems (RDBMS), NoSQL systems, Hadoop, MapReduce. Traditional RDBMS systems are usually not considered as a good enough solution for Big Data. Relatively new NoSQL databases are efficient because they are unstructured systems. The next element is Hadoop, presenting the Apache project, provides a development framework for distributed storage and processing using the MapReduce system. Big Data analytics is a complex process of analyzing large and diverse datasets due to reveal hidden patterns, unknown correlations, or market trends, in order to define appropriate business decisions of companies (Langović, Pažun, 2016). Big Data refers to the size itself, as well as often to the depth, when collecting a huge amount of data in certain domains. The concept of "small and wide data" refers to different sources and learning process from them and their correlations, therefore, more subtle and intelligent approach to data. (Panetta, 2021)

Cloud Computing. Cloud Computing appears as a need of the economy for better information system capabilities on the existing infrastructure or platforms without large investments. The essence of the Cloud Computing technology concept is based on the way of accessing applications hosted in the cloud. Global end-user spending on cloud public services is projected to increase by $23.1 \%$ in 2021 to a total of $\$$ 332.3 billion, compared to $\$ 270$ billion in 2020 . Gartner predicts global end-user spending on public services in the cloud to jump from 242.6 billion in 2019 to 692.1 billion in 2025 , achieving a $16.1 \%$ compound annual growth rate. (Columbus, 2021)

Internet of Things. When it comes to Internet of Things (IoT) concept, there is expectation that more than 15 billion IoT devices will be connected to the company's infrastructure by 2029 , as well as by 2025 , there are expected to be more than 64 billion IoT devices worldwide. (Costello, 2021; Petrov, 2021). Systems such are Oracle IoT Cloud by Oracle, Azure IoT Microsoft, AVS IoT Amazon Web Services (AVS), Xiveli, THING WORK, etc. represent a good platform for con- necting and developing systems with IoT devices. By applying the given solutions, real-time data are obtained from different business applications, i.e., from various business environments, which enable critical decision-making. (Roehrig, 2019)

Artificial intelligence. A characteristic of artificial intelligence (AI) is the ability to perform processes that traditionally require human cognitive function. Predictions are that by 2025, pre-trained AI models will in general be concentrated among $1 \%$ of suppliers, generating responsible use of intelligence as social concern in 2023. By 2025, $10 \%$ of governments will avoid privacy and security concerns by using synthetic populations to train artificial intelligence, as well as $75 \%$ of on-the-job interviews will be recorded and analyzed for use in order to add organizational value and assess the risk. Further prediction is that $50 \%$ of companies will design artificial intelligence orchestration (AI) platforms to operationalize AI. By the maturation of the AI market given concept will be the main category of driving infrastructure, which will result in a tenfold increase in computer requirements. (Vigliarolo, 2021)

\section{Some examples of IT application in tourism industry}

Many Big Data issues are related to the tourism sector. One of them is the difficulty in exchanging information between sources. Organizations generally do not have a standard way of collecting data. However, UNWTO is already working to create a standard statistical framework. Many cities do not have a Big Data strategy (Langović, Pažun, 2020). Areas of application of Big Data systems in tourism organizations are following: revenue management, reputation management, strategic marketing, customer experience, market research.

Marriott is able to gain many competitive advantages by using Big Data analytics. The company uses data to track competing brands and hotels, for identifying new revenue streams outside rooms, such as new facilities and services, therefore, ensures satisfaction of market conditions. However, the main areas of the company are revenue management and customer satisfaction. Revenue management consists of setting optimized prices in order to achieve the best possible profit margins. Marriott's approach to revenue management allows the hotel chain to accurately predict demand or customer behavior patterns. Dynamic price automation requires accurate data from a variety of real-time sources. By integrating and analyzing all this information, Marriott is able to predict customer behavior, understand the impact of its properties compared to competitors in the 
same field, and targeting similar profiles. At the end, the company is able to adjust own pricing strategy even proactively. Starwood hotels began implementing this approach in 2014, shortly before merging with Marriott International in 2016. The hotel chain has invested more than $\$ 50$ million in its revenue optimization system (ROS), which can integrate data from internal and external sources and suggest optimal prices, based on the results of its real-time analysis and demand forecasting. With the help of dynamic automation of pricing, Starwood achieved a 5\% increase in revenue per room in one year, and nowadays Marriott is able to maximize profits. (Dallemand, 2019)

Companies with a tradition whose business is automated with an information system that manages a large amount of data, certain processes of data management or information move to the cloud and thus increase agility and efficiency. Expedia Group has stated that in the next two to three years it has moved $80 \%$ of its critical mobile applications in 2018 from its local data centers to the cloud. TUI AG Group has announced that considers to close own traditional data centers by 2025 in order to accelerate the process of implementing innovative technologies. (GlobalData Thematic Research, 2021). More than $50 \%$ of web traffic comes from a mobile phone. Customers and employees are, as well, part of this traffic. Cloud computing generates access to data and applications so easy that there is no need to be present in the office. This is especially useful during meetings, business trips, etc. In this way it helps to solve one of the weaknesses in the use of mobile systems that create greater accessibility for the management of tourist destinations. (TravelCarma, 2020).

IoT systems are also an important part of hotel or tourism systems used for energy conservation, security management, location information, and system maintenance process management. A boom of IoT technologies will boost the future of the hospitality industry; it will provide a competitive advantage in the market, that is, through the interconnection of devices (sensors, actuators, identification marks, mobile, etc.) via the Internet. An example of actual use is NADIA and its applications for the tourism sector. NADIA was launched in 2017 with the idea of exposing the great potential of IoT in the given industry. The example would be the "Hotel Room" by NADIA. The great potential of NADIA is based on two approaches; the first approach is by service users, i.e. hotel customers can use the application to adjust the temperatures, TV in their hotel rooms, control the lighting, etc. In this way they create a unique experience. On the other hand, the business system or hotel itself has the possibility of remote capacity management. (Bhupal Naik et al., 2019)
Among the new tools used by IoT in smart tourist destinations, one underlined is Web-App for visitors called Be Memories project, an innovative tourist guide that spreads the intangible heritage of the destination with the use of the Internet of Things, and through the cooperation of residents in the role of content creators. This solution was deployed in Ceutí (Spain) and Bristol (United Kingdom). The content is presented in a short video with interviews that visitors and residents can watch and listen while visiting various points of interest in the cities where given type of service is provided, as well as can use Be memories service by their smartphones. (Gomez-Oliva et al., 2019)

Hopper is the company that uses data science, i.e., applied predictive analytics through certain tools that help users in booking airline tickets at the optimal price (Travelport, 2019). The next example is the Intelligent Travel Assistant. Smart reception services, powered by artificial intelligence, become very important in various industries. Travel reservations are only one of the areas where algorithms are highly automated. (Bulanov, 2018; Alteksoft, 2018). Optimized interrupt management that helps users with problems that may occur during traveling, can be automated. It applies mainly to business trips. On a business trip, unpleasant situation can result in significant losses and can have serious consequences for the company. It has become possible to anticipate such disturbances and effectively mitigate losses. The 4Site tool was developed by Cornerstone Information Systems, which enables the efficiency of travel to legal entities through the set of functions for managing travel interruptions in real time (Langović, Pažun, 2020). Further, Amadeus, one of the world's leading distribution systems, has implemented a scheduled recovery system, with the goal of helping airlines reduce travel interruption risks. Kantas, Australia's largest airline, was the first to implement a business improvement system using an interruption control system. Customers who are at distance are not able to assess the environment of the hotel or the quality of hotel rooms or services. Still, there is a possibility that to some extent offers the opportunity to use applications for virtual reality (Yung, Khoo-Lattimore, 2017; Khoo-Lattimore, 2020). Combining virtual assistants and human assistants can also help optimize business performance. (Mirbabaie et al., 2020)

When it comes to personalization in airlines, certain solutions are oriented towards given issue. For example, United Airlines has been analyzing the use of their own website since 2014. The company monitors user behavior through certain historical data. This dataset is used to analyze the needs of users, i.e., to adjust the pages in real time depending 
on the category of users. The results are increasing the communication quality with users. Given form of personalization increases revenue yearly by approximately 15 percent. (Noies, 2014)

Face recognition is likewise applied in the travel and tourism industry. For example, passengers undergo a set of complex control processes in the form of document control. This complexity in given processes requires a lot of time. (Patel, 2018). This technology is currently applied by the ShoCard organization for airlines (Saulat, 2018). In addition to face recognition, hotels can also automate check-in. Such features of hotel products exist in many hotels around the world.

Robots are another type of AI technology that strengthens their presence in the tourism industry. More and more hotels use chatbots or robotic assistants (Figure 1). Virtual voice assistants appear more often in hotels. According to Oracle 2025 hotel report, 78 percent of hotels will upgrade their apartments to voice-controlled devices, and 68 percent will use check-in and check-out robots by 2025 (Oracle Hospitality, 2017). Robot receptionists have become trend in the tourism industry, which has direct implications for the interaction and experience of EU customers and guests. They even take into account aspects of room service, in some of the esteemed Marriott hotels such as St. Regis, Westin and Aloft, Aleka robot was very noticeable. By using artificial intelligence in combination with a maximum probability algorithm, service providers can provide service optimization. The highest probability algorithm uses previous data and suggests the probability of price values (Moraga-Gonzalez, such as hotel/ flight/ cabin reservation. For example, customers can decide whether to book a hotel/ flight/ cabin or wait until the price drops (Ropero, 2011). In addition, the subsets of AI, that is machine learning or neural networks, have been used for analyzing data related to tourism, in forms of association and classification learning, in cases such are forecasting of tourists' expenses, the number of tourist arrivals prediction, as well as in analyzing tourists' profiles, customer experience, etc. (Gajdošík, Marciš, 2019; Parvez, 2020)

When it comes to new term named cultural tourism, "Improving Sustainable Development Policies and Practices to Assess, diversify, and foster Cultural Tourism in European regions and areas" (IMPACTOUR) is the project which supposed to create an innovative and user-friendly methodology and tool based on combination of data analytics algorithms and AI and machine learning strategies in order to measure and assess the impact of cultural tourism on European economic and social development. It has been funded by the H2020 Framework Program of the European Commission, from January 2020 until December 2022, with participation of 12 partners from 10 European countries. (Kalvet et al., 2020)

According to the research conducted by Verdict (2021), in the light of pandemic, AI has been recognized as a major investment area for travel and tourism companies in order to attract and restore confidence among travelers. Based on the poll of 477 responses, conducted in the first quarter of 2021, results show that artificial intelligence will be a major area of investment for companies, with $45 \%$ of the respondents.

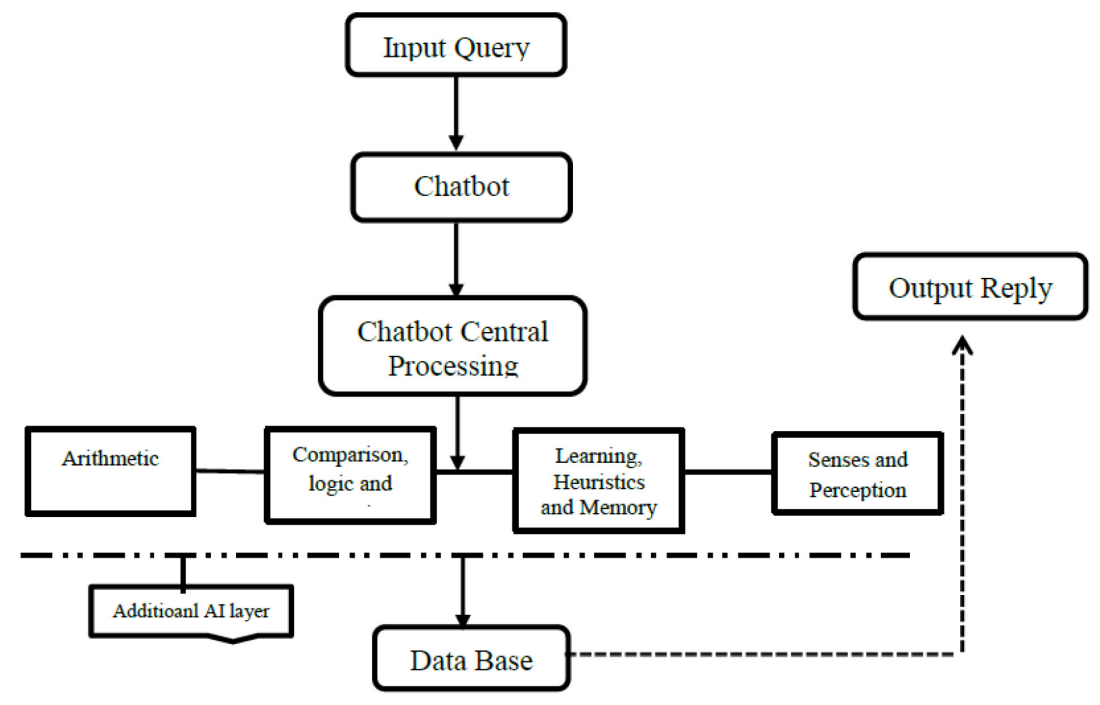

Figure 1. Conceptual framework of tourism bot (Ukpabi et al., 2019).

Wildenbeest, 2008). It suggests the best buying time in terms Next to AI area, following is cybersecurity issues with $35 \%$, of price. Given technology is used in many areas of tourism, 
as well as robotics (31\%), Big Data and machine learning (30\%), IoT and drones (29\%), etc. (Figure 2).

Still, there is opposite side of IT trends implementation and usage. With quite number of positive issues, some negative facts regarding to security, privacy, employees decrease, etc. need to be consider. Despite the fact that artificial intelligence provides financial benefits by replacing employees and providing a unique experience to customers, it still cannot surpass human intelligence (Laurent et al., 2015). Another particularly noticeable challenge in using $\mathrm{AI}$ is data security and privacy, due to chatbots, hotels preserving a past history of shopping, travel, etc. (Kannan, Bernoff, 2019). The main problem with the services provided is that a small malware attack can interfere with the software systems of the companies providing the services. Although AI technology is advanced, small service providers cannot afford mentioned technologies because they require huge investments (Murphy et al., 2017). Chatbots and robots are able to replace the human workforce, to some extent, that is, customers still rely on human labor when it comes to issues involving complexity and urgency. (Lommatzsch, 2018)

\section{Conclusion}

The development of the tourism industry encourages the creation of a large amount of data that needs to be processed. As a consequence of data growth in the modern business environment, the market develops and applies new technologies that enable data management. The importance of informatization of the tourism sector and monitoring of the latest achievements in the field of information and communication technologies is shown by the growth of the share of the branch in the global GDP, as well as share of employees. It is important to take into account the fact that given technologies converge into the resulting organized information system of any business environment.

The pandemic has created an immediate need for virtual workforce and cloud resources to support them on a large scale, accelerating the adoption of public cloud in 2020 and further. Containerization, virtualization and edge computing have quickly become commonplace and encouraged additional cloud-based consumption. Covid-19 brought colossal changes to the travel and tourism sector as airline agents, travel agents, hoteliers and cruise operators had to work from home. Consequently, companies have had to improve their communication channels and infrastructure to ensure that there has been still a centralized system for all who have had access to critical data and resources while working remotely.

From artificial intelligence to small data and chart technology, data and analyst leaders should consider taking advantage of these trends. When Covid-19 has started, organizations that use traditional analytical techniques that rely mostly on large amounts of historical data realized one important fact, that is, many of these models are no longer relevant. In essence, the pandemic has changed everything, making a lot of data useless. In turn, research teams for data and analytics are shifting away from traditional AI techniques, relying on Big Data toward a class of analytics that

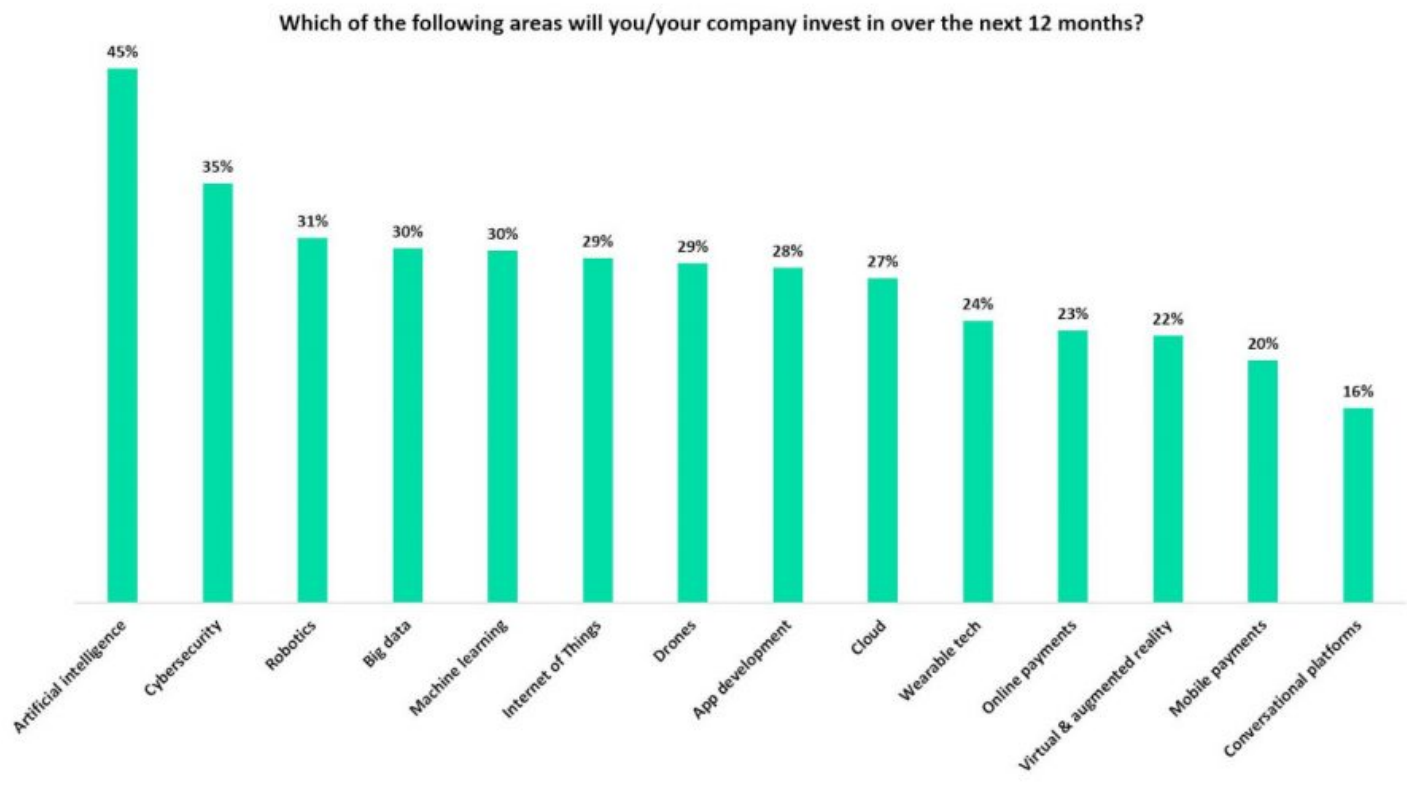

Figure 2. Investing in tourism industry in 2021-2022 (Verdict, 2021).

requires less and more diverse data. These data and analytics 
trends can help organizations and society cope with disruptive change, radical uncertainty. The transition from Big Data to small and broad data is one of Gartner's major data and analytics trends in future (Gartner, 2020). These trends represent business, market, and technological dynamics that data and analyst leaders cannot afford to ignore.

All above-mentioned facts indicate that the tourism industry can generate optimal use of the latest technologies in order to improve efficiency and productivity. Tourism industry products customers will have a higher level of satisfaction. At the same time, tourism systems have better control over processes. Business processes will be largely automated.

In addition, it is necessary to perform an overall analysis of the impact of new forms of technology because their effects are serious. The concept of robotics and artificial intelligence has an impact on both employers, employees and service users. Therefore, there is a need to conduct comprehensive research studies on given technologies in tourism, through critical appraisal.

\section{ORCID iDs}

Brankica Pažun (DD https://orcid.org/0000-0002-9452-5064 Zlatko Langović (D) https://orcid.org/0000-0002-0248-0453

\section{References}

Altexsoft, (2018), Chatbots in Travel: How to Build a Bot that Travelers Will Love,

https://www.altexsoft.com/blog/business/chatbots-intravel-how-to-build-a-bot-that-travelers-will-love/,

(26 April 2021)

Bhupal Naik, D. S., Ramakrishna Sajja, V., Jhansi Lakshmi, P., \& Venkatesulu, D. (2019). An IoT based Architecture for Smart Farming. International Journal of Control and Automation (IJCA), NADIA, 12(9), 31-40. doi: 10.33832/ijca.2019.12.9.04

Bulanov, A. (2018). How Machine Learning and AI Can Improve Travel Services,

https://towardsdatascience.com/how-machine-learningand-ai-can-improve-travel-services-3fc8a88664c4, (26 April 2021)

Columbus, L. (2021). Gartner predicts the public cloud services market will reach $\$ 397.4$ bn by 2022: What you need to know, https://cloudcomputingnews.net/news/2021/may/10/gartner-predicts-thepublic-cloud-services-market-will-reach-397-4bn-by2022-what-you-need-to-know/ (22 April 2021)

Costello, K. (2021). Enterprise infrastructures are changing, posing new opportunities and new threats for I\&O leaders,https://www.gartner.com/smarterwithgartner/gartner-predicts-the-future-of-cloud-and-edgeinfrastructure/ (22 April 2021)

Dallemand, J. (2019). Why is Marriott the Big Data analytics leader in hospitality? [Case] https://blog.datumize.com/big-data-analytics-in-hospitality-marriott-international-case-study (25 April 2021)

Gajdošík T., Marciš M. (2019). Artificial Intelligence Tools for Smart Tourism Development. In: Silhavy R. (eds) Artificial Intelligence Methods in Intelligent Algorithms. CSOC 2019. Advances in Intelligent Systems and Computing, vol 985. Springer, Cham. https://doi.org/10.1007/978-3-030-19810-7_39

Gartner, (2020). https://www.gartner.com/smarterwithgartner/gartner-top-strategic-technology-trends-for2021/ (28 April 2021)

GlobalData Thematic Research, (2021). Cloud Computing: Travel and Tourism Trends,

https://www.hotelmanagement-network.com/features/cloud-computing-travel-and-tourism-trends/ (25 April 2021)

Gomez-Oliva, A., Alvarado-Uribe, J., Concepcion ParraMeroño, M. \& J. Jara, A. (2019). Transforming Communication Channels to the Co-Creation and Diffusion of Intangible Heritage in Smart Tourism Destination: Creation and Testing in Ceutí (Spain), Sustainability, MDPI, Open Access Journal, 11(14), pp 1-30.

IMPACTOUR. Improving Sustainable Development Policies and Practices to Access, Diversify and Foster Cultural Tourism in European Regions and Areas, https://www.impactour.eu/ (28 April 2021)

Kannan, P.V., Bernoff, J. The Future of Customer Service Is AI-Human Collaboration. MIT Sloan Man-agement Review, https://sloanreview.mit.edu/article/the-futureof-customer-service-is-ai-human-collaboration/ (28 April 2021)

Kalvet, T., Olesk, M., Tiits, M., \& Raun, J. (2020). Innovative Tools for Tourism and Cultural Tourism Impact Assessment. Sustainability, 12(18), 7470. doi:10.3390/su12187470

Khoo-Lattimore, C. (2020). Diversity excellence in tourism research: a perspective article, Tourism Review, 75 (1), pp. 33-36. https://doi.org/10.1108/TR-07-2019-0321

Langović, Z., \& Pažun, B. (2016). Virtualization of information resources in tourism organizations. Tour-ism International Scientific Conference Vrnjačka Banja - TISC, 1(2), 536-552. 
Langović, Z., \& Pažun, B. (2020). Contemporary ict concepts in tourism organizations. Tourism Interna-tional Scientific Conference Vrnjačka Banja - TISC, 5(1), 198-214.

Laurent, P., Chollet, T. \& Herzberg, E. (2015). Intelligent automation entering the business world, https://www2.deloitte.com/con-

tent/dam/Deloitte/pt/Documents/strategy/2lu-intelligent-automation-business-world.pdf (28 April 2021)

Lommatzsch, A. (2018), A next generation Chatbot-Framework for public administration. 18th Interna-tional Conference, I4CS 2018, Žilina, Slovakia, Proceedings, 127-141.

Mirbabaie, M., Stieglitz, S., Brünker, F., Hofeditz, L., Ross, B., R. J. Frick, N. (2020). Understanding Col-laboration with Virtual Assistants - The Role of Social Identity and the Extended Self. Bus Inf Syst Eng 63, 21-37. https://doi.org/10.1007/s12599-020-00672-x

Moraga-Gonzalez, J. \& Wildenbeest, M. (2008). Maximum likelihood estimation of search costs, European Economic Review, 52(5,) pp. 820-848.

Murphy, J., Hofacker, C., Gretzel, U. (2017). Dawning of the Age of Robots in Hospitality and Tourism: Challenges for Teaching and Research. European Journal of Tourism Research, 15, 104 - 111.

Noyes, K. (2014). For the airline industry, big data is cleared for take-off,

https://fortune.com/2014/06/19/big-data-airline-industry/ (27 April 2021)

Oracle Hospitality, (2017). HOTEL 2025 emerging technologies destined to reshape our business,

https://www.oracle.com/webfolder/s/delivery_production/docs/FY16h1/doc31/Hotels-2025-v5a.pdf

(27 April 2021)

Panetta, K. (2021). From artificial intelligence to small data and graph technology, data and analytics leaders should think about leveraging these trends, https://www.gartner.com/smarterwithgartner/gartner-top-10-data-and-analytics-trends-for-2021/

April 2021)

Parvez, M.O. (2020), Use of machine learning technology for tourist and organizational services: high-tech innovation in the hospitality industry, Journal of Tourism Futures, Vol. ahead-of-print No. ahead-of-print. https://doi.org/10.1108/JTF-09-2019-0083

Patel, V. (2018). Airport passenger processing technology: a biometric airport journey, $\mathrm{PhD}$ Dissertations and Master's Theses. 385, https://commons.erau.edu/edt/385/ (27 April 2021)
Pažun, B., \& Langović, Z. (2020). Cloud computing concept in education systems. Serbian Journal of En-gineering Management, 5(2), 25-32.

Pažun, B., \& Langović, Z. (2019). Contemporary information system development methodologies in tour-ism organizations. Tourism International Scientific Conference Vrnjačka Banja - TISC, 4(1), 467-481.

Petrov, C. (2021). 47 Stunning Internet of Things Statistics 2021 [The Rise Of IoT],

https://techjury.net/blog/internet-of-things-statistics/\#gref (22 April 2021)

Roehrig, P. (2019). Insights for Getting and Staying Ahead in the Digital Economy, https://www.cognizant.com/whitepapers/11-insights-for-getting-and-staying-ahead-in-the-digitaleconomy-codex5163.pdf (24 April 2021)

Ropero, A.M. (2011). Dynamic Pricing Policies of Hotel Establishments in an Online Travel Agency, Tour-ism Economics, 17(5), pp. 1087-1102.

Saulat, A. (2018). Four ways AI is re-imagining the future of travel", available at: www.mindtree.com/blog/fourways-ai-re-imagining-future-travel, (27 April 2021)

Statista, (2021), https://www.statista.com/markets/420/travel-tourism-hospitality/ (20 April 2021)

TravelCarma, (2020). Why Cloud Computing is the Future of the Travel Industry,

https://blog.travelcarma.com/2020/02/19/why-cloudcomputing-is-the-future-of-the-travel-industry-2/ (25 April 2021)

Travelport, (2019). 8 travel brands using data and AI to improve customer experience, https://blog-digital.travelport.com/8-travel-brands-using-data-and-ai-to-improve-customer-experience, (26 April 2021)

Ukpabi, D. C., Aslam, B., \& Karjaluoto, H. (2019). Chatbot adoption in tourism services: A conceptual exploration. Robots, Artificial Intelligence, and Service Automation in Travel, Tourism and Hospitality, Emerald Publishing Limited, 105-121.

UNWTO (World Tourism Organization), (2021). UNWTO World Tourism Barometer and Statistical Annex, March 2021, https://www.e-unwto.org/doi/epdf/10.18111/wtobarometereng.2021.19.1.2, (20 April 2021).

Verdict research, (2021). https://www.hotelmanagementnetwork.com/news/artificial-intelligence-a-major-investment-area-for-travel-and-tourism-companiespoll (28 April, 2021)

Vigliarolo, B. (2021). Gartner: The future of AI is not as rosy 
as some might think,

https://www.techrepublic.com/article/gartner-the-future-

of-ai-is-not-as-rosy-as-some-might-think/ (24 April 2021)

Yung, R. \& Khoo-Lattimore, C. (2017). New realities: a systematic literature review on virtual reality and augmented reality in tourism research. Current Issues in Tourism. 22. 1-26. 10.1080/13683500.2017.1417359 